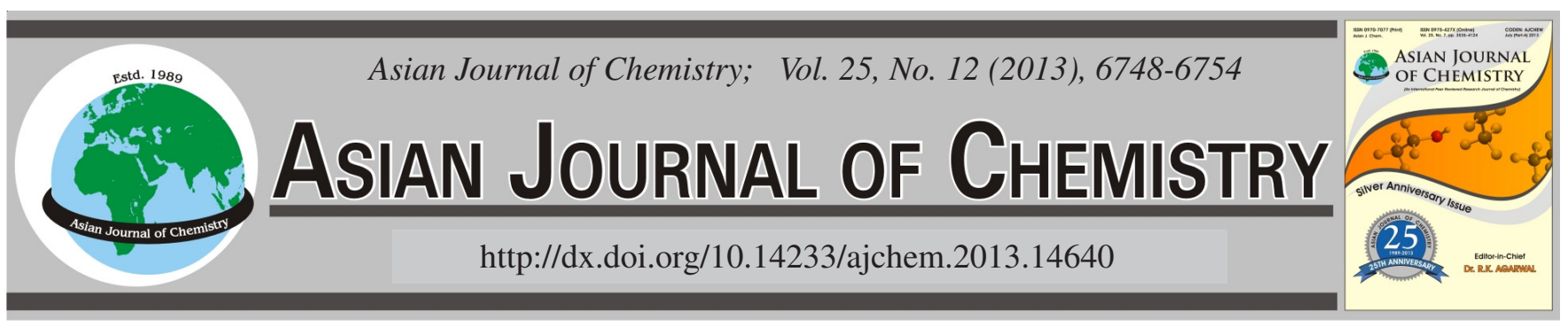

\title{
Microwave Synthesis of Some New 1,3-Oxazepine Compounds as Photostabilizing Additives for Poly(vinyl chloride) Films
}

\author{
Nadia Salih ${ }^{1, *}$, Jumat SAlimon $^{1},{\text { Emad } \text { Yousif }^{2} \text { and Ayad Hamed }}^{3}$
}

${ }^{1}$ School of Chemical Sciences and Food Technology, Faculty of Science and Technology, Universiti Kebangsaan Malaysia, 43600 Bangi, Selangor, Malaysia

${ }^{2}$ Department of Chemistry, College of Science, Al-Nahrain University, Baghdad, Iraq

${ }^{3}$ Department of Chemistry, College of Education, Tikrit University, Tikrit, Iraq

*Corresponding author: E-mail: nadiaalnami@yahoo.com

(Received: 29 September 2012;

Accepted: 29 May 2013)

AJC-13564

\begin{abstract}
The work presented the synthesis of four new compounds containing 1,3-oxazepine and 1,3,4-oxadiazole [I-IV] by microwave assisted organic synthesis method through the condensation reaction of 2-[4-(arylidene)phenyl-1,3,4-oxadiazole-5-thiol] with maleic anhydride under variable microwave power $(180,510)$ watt. The structure of the synthesized compounds was characterized using available spectroscopic methods ( $\left.{ }^{1} \mathrm{H}-\mathrm{NMR}, \mathrm{FTIR}\right)$. The photo stabilization of poly(vinyl chloride) films by using 3-oxazepine and 1,3,4-oxadiazole compounds was investigated. The PVC films containing concentration of complexes $0.5 \%$ by weight were produced by the casting method in tetrahydrofuran. The photostabilization activities of these compounds were determined by monitoring the carbonyl, polyene and hydroxyl indices with irradiation time. The changes in viscosity average molecular weight of PVC with irradiation time were also tracked (using THF as a solvent). The quantum yield of the chain scission $\left(\Phi_{c s}\right)$ of these complexes in PVC films was evaluated and found to range between $4.27 \times 10^{-8}$ and $7.41 \times 10^{-8}$. Results showed that the rate of photostabilization of PVC in the presence of the additive followed the trend: I > II > III > IV. According to the experimental results, several mechanisms were suggested depending on the structure of the additive. Among them, UV absorption, peroxide decomposer and radical scavenger for photostabilizer mechanisms were suggested.
\end{abstract}

Key Words: Microwave synthesis, 1,3-Oxazepine, 1,3,4-Oxadiazole, Photochemistry, PVC, Photostabilizer, UV absorber.

\section{INTRODUCTION}

Microwave assisted organic reaction enhancement (MORE) is now days a well established technique for synthesis of various heterocyclic compounds ${ }^{1-3}$ through cycloaddition reactions, especially in the cases where high temperature are required. These synthesis can be carried out safely in microwave reactor with remarkable rate enhancement, these mainly due to the super heating effect. The ability of microwave to rapidly heat the reaction much above the boiling points of the solvent ${ }^{4,5}$. There is a great interest in the photo-oxidative degradation of polymeric materials because macromolecules have increasingly widespread commercial applications. Synthetic polymeric compound, semi synthetic compound and natural compound are when exposed to the environment ${ }^{6}$. All commercial organic polymers degrade in air when exposed to sunlight as the energy of sunlight is sufficient to cause the breakdown of polymeric C-C bonds as a consequence of degradation.

The resulting smaller fragments do not contribute effectively to the mechanical properties and the polymeric material because brittle in nature. Thus the life of thermoplastics for outdoor applications becomes limited due to weathering 7 . Almost all synthetic polymers require stabilization against the adverse effect with the development of synthetic resins it became necessary to look for ways and means to prevent or at least reduce, the damage caused by the environmental parameters, light, air and heat. This can be achieved through addition of special chemicals, light stabilizers or UV stabilizers, that have to be adjusted to the nature of the resin and the specific application considered. The photostabilization of polymers may be achieved in many ways. The following stabilizing systems have been developed, which depend on the action of stabilizer: (1) light screeners, (2) UV absorbers, (3) excited state quenchers, (4) peroxide decomposers and (5) free radical scavengers, of these it is generally believed that types 3, $\mathbf{4}$ and $\mathbf{5}$ are the most effective ${ }^{8}$. Most or, indeed all stabilizers are believed to be multifunctional in their mode operation. This view is complicated by the fact that the mechanism involved in photo-oxidation and these, in turn depend on the polymer structure and other variables, such as manufacturing, operation, processing, conditions, etc. ${ }^{9}$. 
As part of our on-going research on the photostabilization of polymers, the photostabilization of PVC was studied using a new four heterocyclic compounds containing 1,3-oxazepine and 1,3,4-oxadiazole and it is hoped that the incorporation of these two heterocyclic units may enhance the photostability of PVC.

\section{EXPERIMENTAL}

Melting points were measured on an Electro thermal melting point apparatus sartorius BL-210S and were uncorrected. The IR-spectra were recorded on Perkins-Elmer Fourier-Transforme Infrared Spectrophotometer (FR-IR) as potassium bromide pelts.

${ }^{1} \mathrm{H}$ NMR spectra were performed on a Bruker-NMR, ultra shield (300) MHz, Switzerland spectrometer using DMSO- $d_{6}$ as solvent and TMS as internal standard. All the chemicals used in this research (solid, liquid) were obtained from Merck, GCC, Fluka and BDH companies. Compounds (A-D) namely: 5-(4-arylidene)-phenyl-1,3,4-oxadiazole was synthesized using a published methods ${ }^{10}$. The 1,3-oxazepine compounds were all prepared by the method previously described ${ }^{11}$.



where $\mathrm{X}=-\mathrm{OH},-\mathrm{N}\left(\mathrm{CH}_{3}\right)_{2},-\mathrm{H},-\mathrm{Cl}[\mathrm{I}]$, [II], [III], [IV]

General procedure for the synthesis of compounds (IIV). (Z)-2,3-dihydro-(5-mercapto-1,3,4 oxadiazol-2-yl)phenyl-2-(substituted)-1,3,4-oxazepine- 4,7-dione: Recently a new method which has been discovered involves direct addition of maleic anhydride to the $(\mathrm{C}=\mathrm{N})$ double bond of Schiff base and according to this method four new compounds were synthesized having the above general name using microwave approach instead of refluxing method ${ }^{11}$.

A mixture of $(0.001 \mathrm{~mol})$ of compounds (A-D) and (0.001 mole) of maleic anhydride were ground with a mortar, mixed, dried and subjected to microwave irradiation for 2-3 min, after completion the reaction mixture was cooled to room temperature and the solid obtained was recrystallized twice from absolute ethanol. Some of the physical data for these four compounds are listed in Table-1.

Films preparation: The polymer matrix used in this study was PVC $(\mathrm{K}$ value $=67$, degree of polymerization $=800)$ supplied by Petkim (Turkey) was re-precipitated from THF solution by alcohol several times and finally dried under vacuum at room temperature for $24 \mathrm{~h}$. PVC films were prepared as follows. The best solvent for PVC is THF. The films were prepared by dissolving $5 \mathrm{~g}$ of PVC in $100 \mathrm{~g}$ of THF under vigorous stirring for $0.5 \mathrm{~h}$. It was necessary to control the hygrometry and the rate of evaporation of solvent during casting to maintain good optical quality and very limited turbidity. The film transmission should be greater than $80 \%$ in the nearUV range. After $3 \mathrm{~h}$, the solution was spread on a slide stainless steel model (250-120-0.5 mm) and air-dried for $24 \mathrm{~h}$. After the solvent evaporation, the samples were dried in a vacuum at room temperature for $30 \mathrm{~h}$. The thickness of the resulting PVC film $(30 \mu \mathrm{m})$ was measured by a micrometer type 2610 A, Germany.

Accelerated testing technique: Accelerated weatherometer Q.U.V. Tester (Q. panel, company, USA), was used for irradiation of polymers films. The accelerated weathering tester contains stainless steel plate, which has two holes in the front side and a third one behind. Each side contains a lamp (type Fluorescent Ultraviolet Lights) 40 watt each. These lamps are of the type UV-B 313 giving spectrum range between 290$360 \mathrm{~nm}$ with a maximum wavelength at $313 \mathrm{~nm}$. The polymer film samples were vertically fixed parallel to the lamps to make sure that the UV incident radiation is perpendicular to the samples. The irradiated samples are rotated from time to time

IV


to ensure that the intensity of light incident on all samples is the same.

Measuring the photodegradation rate of polymer films using infrared spectrophotometery: The degree of photodegradation of polymer film samples was followed by monitoring FTIR spectra in the range $4000-400 \mathrm{~cm}^{-1}$ using FTIR 8300 Shimadzu spectrophotometer. The position of carbonyl absorption is specified at $1722 \mathrm{~cm}^{-1}$, polyene group at $1602 \mathrm{~cm}^{-1}$ and the hydroxyl group at $3500 \mathrm{~cm}^{-1}{ }^{8}$. The progress of photodegradation during different irradiation time was followed by observing the changes in carbonyl and polyene peaks. Then carbonyl $\left(\mathrm{I}_{\mathrm{co}}\right)$, polyene $\left(\mathrm{I}_{\mathrm{po}}\right)$ and hydroxyl $\left(\mathrm{I}_{\mathrm{OH}}\right)$ indices were calculated by comparison of the FTIR absorption peak at 1722,1602 and $3500 \mathrm{~cm}^{-1}$ with reference peak at 1328 $\mathrm{cm}^{-1}$, respectively. This method is called band index method which includes ${ }^{8}$.

$$
I_{s}=\frac{A_{s}}{A_{r}}
$$

$A_{s}=$ Absorbance of peak under study, $A_{r}=$ Absorbance of reference peak, $I_{s}=$ Index of group under study.

Actual absorbance, the difference between the absorbance of top peak and base line (A top peak - A base line) is calculated using the base line method ${ }^{12}$.

Determination of average molecular weight using viscometry method $\left(\overline{\mathbf{M}}_{\mathbf{v}}\right)$ : The viscosity property was used to determine the average molecular weight of polymer, using the Mark Houwink relation ${ }^{13}$.

$$
[\eta]=\mathrm{K} \overline{\mathrm{M}}_{\mathrm{v}}^{\alpha}
$$

[ $\eta]=$ the intrinsic viscosity. $\mathrm{K}$ and $\alpha$ are constants depend upon the polymer-solvent system at a particular temperature.

The intrinsic viscosity of a polymer solution was measured with an Ostwald U-tube viscometer. Solutions were made by dissolving the polymer in a solvent $(\mathrm{g} / 100 \mathrm{~mL})$ and the flow times of polymer solution and pure solvent are $t$ and $t_{0}$, respectively. Specific viscosity $\left(\eta_{\mathrm{sp}}\right)$ was calculated as follows:

$$
\eta_{\mathrm{re}}=\frac{\mathrm{t}}{\mathrm{t}_{0}}
$$

$\eta_{\mathrm{re}}=$ Relative viscosity

$$
\eta_{\mathrm{sp}}=\eta_{\mathrm{re}}-1
$$

The single-point measurements were converted to intrinsic viscosities by the relation 2 .

$$
[\eta]=\left(\frac{\sqrt{2}}{\mathrm{c}}\right)\left(\eta_{\mathrm{sp}}-\ln \eta_{\mathrm{re}}\right)^{1 / 2}
$$

$\mathrm{C}=$ Concentration of polymer solution $(\mathrm{g} / 100 \mathrm{~mL})$.

By applying eqn. 5, the molecular weight of degraded and virgin polymer can be calculated. Molecular weights of PVC with and without additives were calculated from intrinsic viscosities measured in THF solution using the following equation:

$$
[\eta]=4.17 \times 10^{-4} \mathrm{Mv}^{0.6}
$$

The quantum yield of main chain scission $\left(\Phi_{\mathrm{cs}}\right)^{14}$ was calculated from viscosity measurement using the following relation $(7)$.

$$
\phi_{\mathrm{cs}}=\left(\frac{\mathrm{CA}}{\overline{\mathrm{M}}_{\mathrm{v}, \mathrm{o}}}\right) \frac{\left[\left(\frac{\left[\eta_{\mathrm{o}}\right]}{[\eta]}\right)^{1 / \alpha}-1\right]}{\mathrm{I}_{\mathrm{o}} \mathrm{t}}
$$

where: $\mathrm{C}=$ concentration; $\mathrm{A}=$ Avogadro's number; $\left(\overline{\mathrm{M}}_{\mathrm{v}, \mathrm{o}}\right)=$ the initial viscosity-average molecular weight; $\left[\eta_{\mathrm{o}}\right]=$ intrinsic viscosity of PVC before irradiation; $\mathrm{I}_{\mathrm{o}}=$ incident intensity and $\mathrm{t}=$ irradiation time in second.

\section{RESULTS AND DISCUSSION}

In the present work four new compounds of 1,3-oxazepines, general naming: (Z)-2,3-dihydro-3-[4-(5-mercapto-1,3,4oxadiazole-2-yl)-phenyl-2-(substituted)-1,3-oxazepine-4,7dione] [I-IV] were prepared in good yields through the cycloaddition reactions of compounds (A-D), 2-(4-arylidene)phenyl-1,3,4-oxadiazole-5-thiol with maleic anhydride under microwave irradiation using a domestic microwave oven. All of the products obtained in good yields (70-87) \% and the optimum period of reaction time was found to be within 2-3 $\min$.

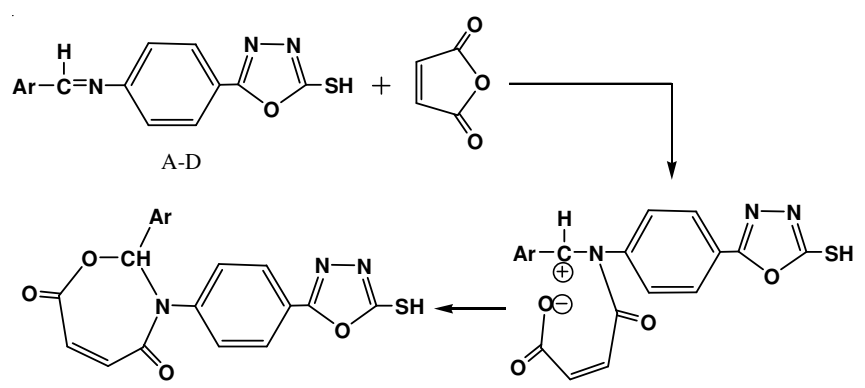

The structures of these four compounds were characterized by spectral data, the IR-spectra of these compounds shows the appearance of the absorption bands at (1704-1610) $\mathrm{cm}^{-1}$ characteristic to $(\mathrm{C}=\mathrm{O})$ of (lactone-lactam) and the disappearing the two absorption bands at (1950-1800) $\mathrm{cm}^{-1}$ of pure maleic anhydride. Table-2 shows the key IR-spectral data.

The ${ }^{1} \mathrm{H}$ NMR spectrum of compound (1) showed the following characteristic signals: one broad singlet in the region (9.8) ppm integrating for one proton which assigned to $(-\mathrm{O}-\mathrm{H})$ being broad and shifted to the low field, this probably due to intermolecular hydrogen bonding. The spectrum also showed one singlet in the region (10.5) ppm integrating for one proton which assigned to $(\mathrm{N}-\mathrm{H})$. The proton of $(\mathrm{S}-\mathrm{H})$ group exhibited singlet in the region (2.8-3.0) ppm and thus explain the occurring of the tautomerism phenomena in this compound:<smiles>S=c1[nH]nc(C#CC#Cc2nnco2)o1</smiles>

The two protons of cis olefine $(\mathrm{CH}=\mathrm{CH})$ - for oxazepine ring exhibit signals at (6.49-6.94) and appeared as doublet - doublet. The resonance peaks appeared at (7.4-7.7) ppm doublet-doublet could be assigned to benzene ring attached to oxazepine and oxadiazole rings. 


IR CHARACTERISTIC BANDS AND THEIR LOCATIONS OF THE 1,3,4-OXADIAZOLE-1,3-OXAZEPINE COMPOUNDS [I-IV]

The collection of spectral data (IR, ${ }^{1} \mathrm{H}$ NMR) gave good evidence for structures given to these compounds. Table-3 showed ${ }^{1} \mathrm{H}$ NMR spectral data for [I-IV] compounds.

The oxazepine-oxadiazole compounds were used as additives for the photostabilization of PVC films. In order to study the photochemical activity of these additives for the photostabilization of PVC films, the carbonyl and polyene indices were monitored with irradiation time using IR spectrophotometry. The irradiation of PVC films with UV light of wavelength, $\lambda=313 \mathrm{~nm}$ led to a clear change in the FTIR

TABLE-3

${ }^{1} \mathrm{H}$ NMR SPECTRA DATA $(\boldsymbol{\delta}, \mathrm{ppm})$ OF THE $1,3,4$-OXADIAZOLE-1,3-OXAZEPINE COMPOUNDS [1-4]

Proton values $(\delta, \mathrm{ppm})$

\begin{tabular}{|c|c|c|c|c|c|c|c|}
\hline \multirow[b]{2}{*}{ Structure } & \multicolumn{7}{|c|}{ Proton values $(\delta, \mathrm{ppm})$} \\
\hline & $\begin{array}{c}\mathrm{C}-\mathrm{H} \\
\text { (aromatic) }\end{array}$ & $\mathrm{CH}=\mathrm{CH}$ & $\mathrm{N}-\mathrm{H}$ & $\mathrm{O}-\mathrm{H}$ & $\mathrm{S}-\mathrm{H}$ & $\mathrm{O}-\mathrm{CH}-\mathrm{N}$ & Others \\
\hline & $6.60-7.70$ & $6.49-6.94$ & 10.50 & 9.80 & 3.00 & 7.35 & - \\
\hline & $6.60-7.01$ & $6.42-6.90$ & 9.66 & - & 2.90 & 7.40 & $\mathrm{~N}\left(\mathrm{CH}_{3}\right)_{2} 2.85$ \\
\hline & $6.60-7.19$ & $6.42-6.94$ & 10.20 & - & 2.80 & 7.30 & - \\
\hline & $6.60-7.20$ & $6.43-6.94$ & - & - & 3.00 & 7.30 & - \\
\hline
\end{tabular}


spectrum $^{12}$, as shown in Fig. 1. Appearance of bands at 1772 and $1724 \mathrm{~cm}^{-1}$, were attributed to the formation of carbonyl groups related to chloroketone and to aliphatic ketone, respectively. A third band was observed at $1604 \mathrm{~cm}^{-1}$, related to polyene group. The hydroxyl band appeared at $3500 \mathrm{~cm}^{-1}$ was annotated to the $-\mathrm{OH}$ of the hydroperoxides group as shown in Scheme-I.

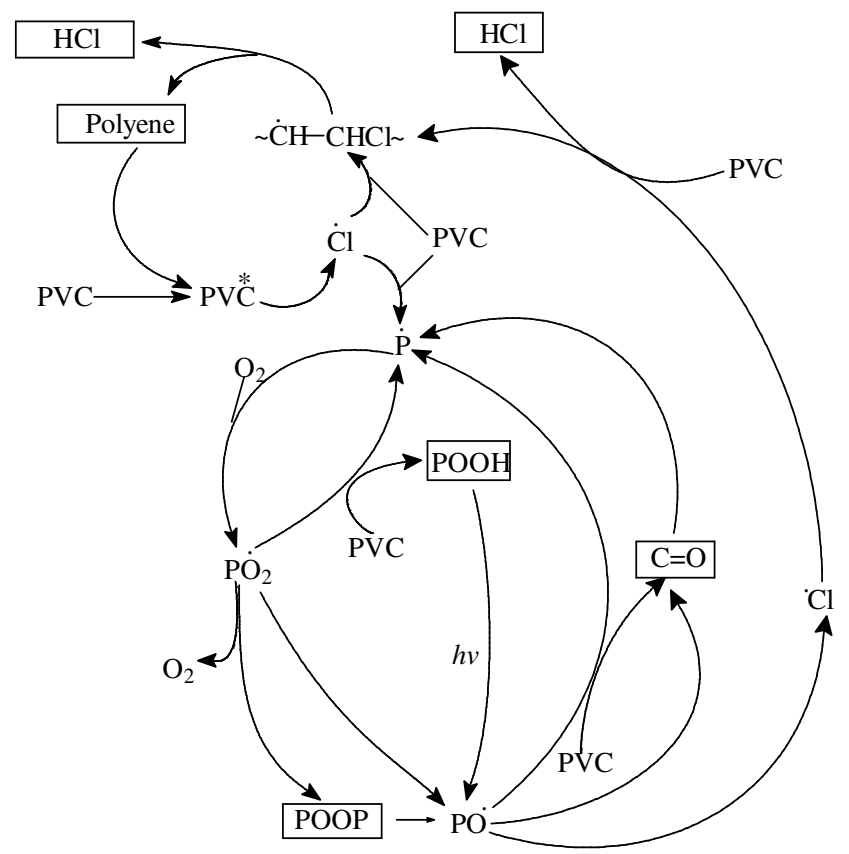

Scheme-I: Photooxidation reaction scheme of PVC

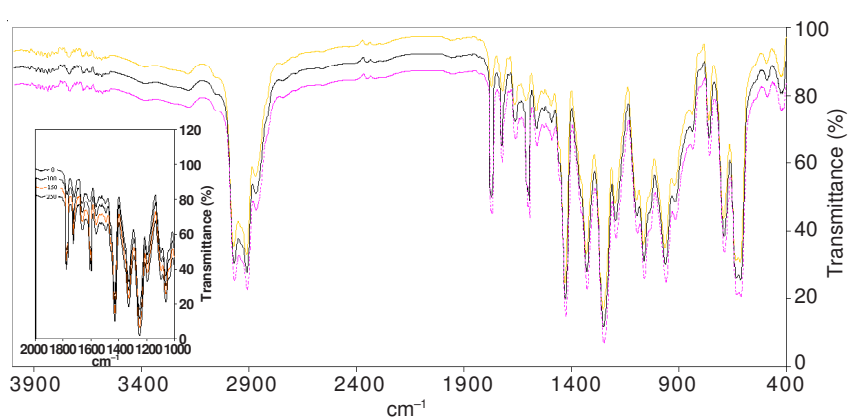

Fig. 1. Change in IR spectrum of PVC film $(30 \mu \mathrm{m})$ in the presence of $\mathbf{I}$ compound

The absorption of the carbonyl, polyene and hydroxyl groups was used to follow the extent of polymer degradation during irradiation. This absorption was calculated as carbonyl index $\left(\mathrm{I}_{\mathrm{co}}\right)$, polyene index $\left(\mathrm{I}_{\mathrm{po}}\right)$ and hydroxyl index $\left(\mathrm{I}_{\mathrm{OH}}\right)$. It is reasonable to assume that the growth of carbonyl index is a measure to the extent of degradation. However, in Fig. 2, the $\mathrm{I}_{\mathrm{co}}$ of IV, III, II and I showed lower growth rate with irradiation time with respect to the PVC control film without additives. Since the growth of carbonyl index with irradiation time is lower than PVC control (Fig. 2). It is suitable to conclude that these additives might be considered as photostabilizers of PVC polymer. Since efficient photostabilizer shows a longer induction period, therefore, the $\mathbf{I}$ is considered as the most active photostabilizer, followed by II, III and SP which is the least active. Just like carbonyl, polyene compounds are also produced

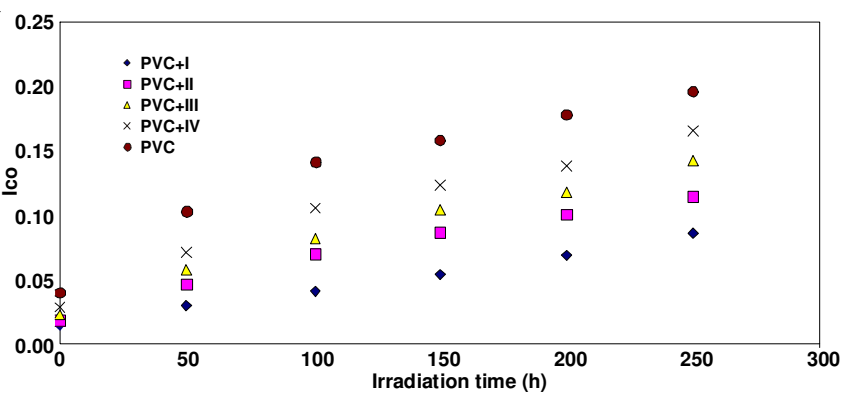

Fig. 2. Relationship between the carbonyl index and irradiation time for PVC films (30 $\mu \mathrm{m}$ thickness) containing different additives. Concentration of additives is fixed at $0.5 \%$ by weight

during photodegradation of PVC. Therefore, polyene index $\left(\mathrm{I}_{\mathrm{PO}}\right)$ could also be monitored with irradiation time in the presence and absence of these additives (Fig. 3).

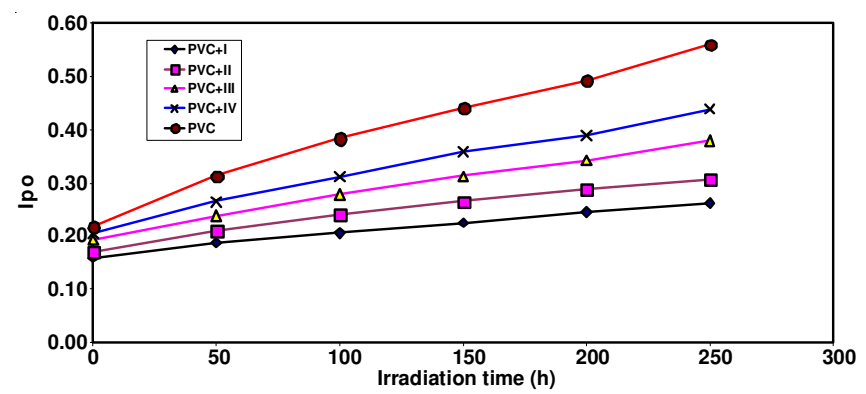

Fig. 3. Relationship between the polyene index and irradiation time for PVC films (30 $\mu \mathrm{m}$ thickness). Containing different additives, concentration of additives are fixed at $0.5 \%$ by weight

Hydroxyl species were produced during photodegradation of PVC. Therefore, hydroxyl index $\left(\mathrm{I}_{\mathrm{OH}}\right)$ was monitored with irradiation time for PVC and with additives. Fig. 4 showed lower growth rate of hydroxyl index of IV, III, II and I with irradiation time compared to PVC blank.

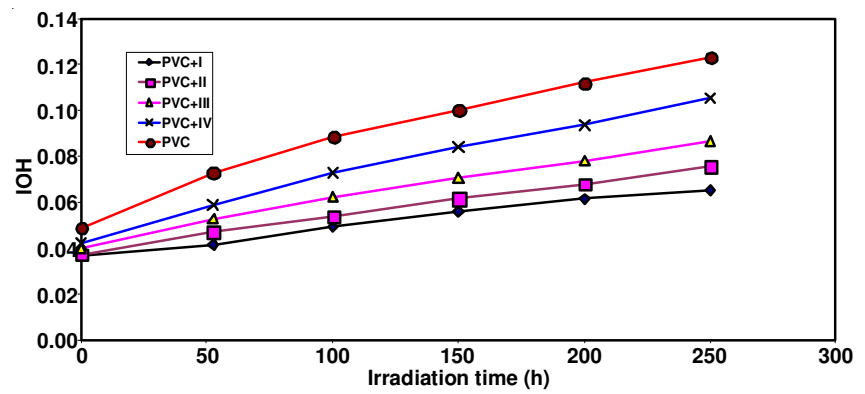

Fig. 4. Relationship between the hydroxyl index and irradiation time for PVC films (30 $\mu \mathrm{m}$ thickness). Containing different additives, concentration of additives are fixed at $0.5 \%$ by weight

Variation of PVC molecular weight during photolysis in the presence of 1,3-oxazepine and 1,3,4-oxadiazole compounds: Analysis of the relative changes in viscosity average molecular weight $\left(\overline{\mathrm{M}}_{\mathrm{v}}\right)$, has been shown to provide a versatile test for random chain scission. Fig. 5 shows the plot of $\overline{\mathrm{M}} \mathrm{v}$ versus irradiation time for PVC film with and without $0.5 \%$ (wt/wt) of the selected additives, with absorbed light intensity of $1.052 \times 10^{-8}$ ein $\mathrm{dm}^{-3} \mathrm{~s}^{-1} . \overline{\mathrm{M}} \mathrm{v}$ is measured using eqn. 4 with THF as a solvent at $25^{\circ} \mathrm{C}$. 


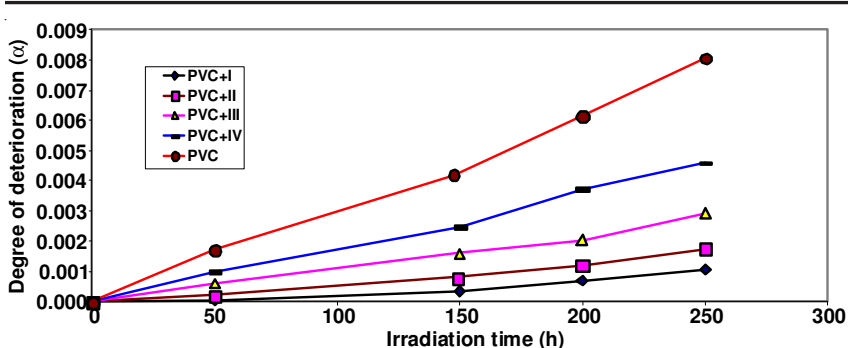

Fig. 5. Changes in the viscosity-average molecular weight $\left(\overline{\mathrm{M}}_{\mathrm{v}}\right)$ during irradiation of PVC films $(30 \mu \mathrm{m})$ and with $0.5 \mathrm{wt} \%$ of additives

It is worth mentioning that traces of the films with additives are not soluble in THF indicating that cross-linking or branching in the PVC chain does occur during the course of photolysis ${ }^{14,15}$. For better support of this view, the number of average chain scission (average number cut per single chain) $(\mathrm{S})^{16}$ was calculated using the relation (8):

$$
\mathrm{S}=\frac{\overline{\mathrm{M}}_{\mathrm{v}, \mathrm{o}}}{\mathrm{M}_{\mathrm{v}, \mathrm{t}}}-1
$$

Where $\overline{\mathbf{M}}_{\mathrm{v}, \mathrm{o}}$ and $\overline{\mathrm{M}}_{\mathrm{v}, \mathrm{t}}$ are viscosity average molecular weight at initial (o) and t irradiation time, respectively. The plot of $\mathrm{S}$ versus time is shown in Fig. 6. The curve indicates an increase in the degree of branching such as that might arise from crosslinking occurrence. It is observed that insoluble material was formed during irradiation which provided additional evidence to the idea that cross-linking does occur ${ }^{8}$.

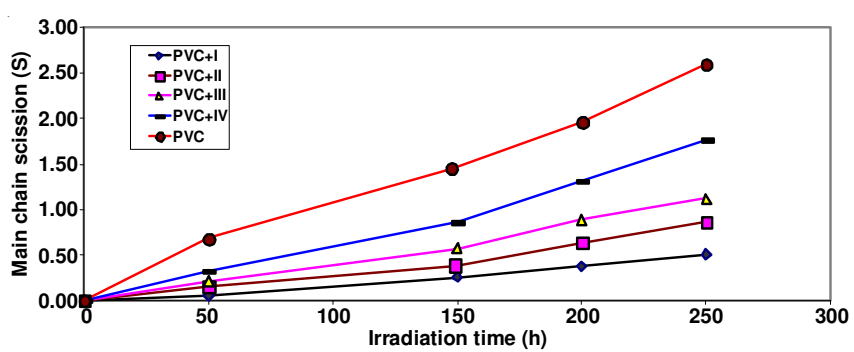

Fig. 6. Changes in the main chain scission (S) during irradiation of PVC films $(30 \mu \mathrm{m})$ and with $0.5 \mathrm{wt} \%$ of additives

For randomly distributed weak bond links, which break rapidly in the initial stages of photodegradation, the degree of deterioration $^{17}(\alpha)$ is given as:

$$
\alpha=\frac{\mathrm{m} . \mathrm{s}}{\overline{\mathrm{M}}_{\mathrm{v}}}
$$

where $\mathrm{m}$ is the initial molecular weight.

The plot of $\alpha$ as a function of irradiation time is shown in Fig. 7.

The values of $\alpha$ of the irradiated samples are higher when additives are absent and lower in the presence of additives compared to the corresponding values of the additive free PVC. In the initial stages of photodegradation of PVC, the value of $\alpha$ increases rapidly with time, this indicates a random breaking of bonds in the polymer chain.

Another way ${ }^{18}$ of degradation reaction characterization is the measurement of the quantum yield of the chain scission $\left(\Phi_{\mathrm{cs}}\right)$. The quantum yield for chain scission was calculated for

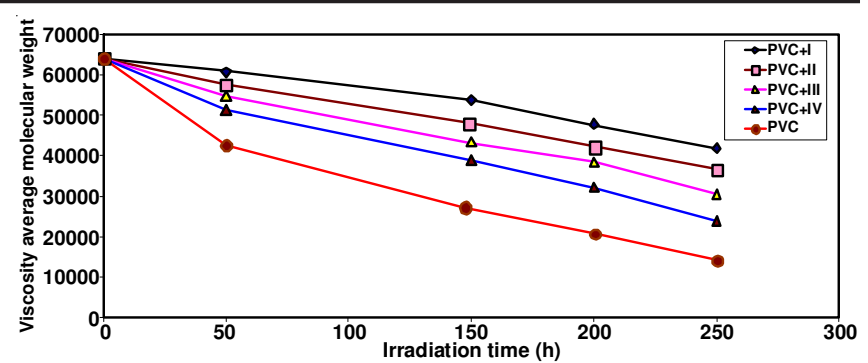

Fig. 7. Changes in the degree of deterioration $(\alpha)$ during irradiation of PVC films $(30 \mu \mathrm{m})$ and with $0.5 \mathrm{wt} \%$ of additives

PVC films with and without $0.5 \%$ (wt/wt) of additive mentioned above using relation (5). The $\Phi_{\mathrm{cs}}$ values for complexes are tabulated in Table-4.

TABLE-4

QUANTUM YIELD $\left(\Phi_{c)}\right)$ FOR THE CHAIN SCISSION FOR PVC

FILMS $(30 \mu \mathrm{m})$ THICKNESS WITH AND WITHOUT $0.5(\mathrm{wt} / \mathrm{wt})$ ADDITIVE AFTER $250 \mathrm{~h}$ IRRADIATION TIME

\begin{tabular}{cc} 
Additive $(0.5 \%$ wt $)$ & Quantum yield of main chain scission $\left(\Phi_{\mathrm{cs}}\right)$ \\
\hline PVC + I & $4.27 \mathrm{E}-08$ \\
PVC + II & $5.01 \mathrm{E}-08$ \\
PVC + III & $6.49 \mathrm{E}-08$ \\
PVC + IV & $7.41 \mathrm{E}-08$ \\
PVC (blank) & $8.59 \mathrm{E}-05$
\end{tabular}

The $\Phi_{\mathrm{cs}}$ values for PVC films in the presence of additive are less than that of additive free PVC (control), which increase in the order:

\section{I, II, III, IV and PVC}

The explanation for low values of $\Phi_{\mathrm{cs}}$ is that in macromolecule of PVC, the energy is absorbed at one site and then the electronic excitation is distributed over many bonds so that the probability of a single bond breaking is small, or the absorbed energy is dissipated by non reactive processes ${ }^{8}$.

It is well established that the quantum yield $\left(\Phi_{\mathrm{cs}}\right)$ increases with increasing temperature around the glass transition temperature, $\left(\mathrm{T}_{\mathrm{g}}\right)$ of the amorphous polymer and around the melting temperature of crystalline polymers. In present study, the photolysis of PVC film is carried out at $35-45^{\circ} \mathrm{C}$ well below the glass transition temperature $\left(\mathrm{T}_{\mathrm{g}}\right.$ of $\left.\mathrm{PVC}=80^{\circ} \mathrm{C}\right)$. Therefore, the $\Phi_{\mathrm{cs}}$ dependency on temperature is not expected to be observed.

1,3-Oxazepine stabilize PVC by different mechanisms such as UV absorber, screener or by radical scavenger. These stabilizers provide good long-term stability and are usually referred to these mechanisms. The most probable mechanisms involved in a photostabilization is the The hydroxyl group of the additive might acts as radical scavenger for photostabilization process. Therefore this Schiff bases, besides acting as UV absorber may also act as radical scavenger additives ${ }^{19}$ (Scheme-II).

The rings of oxazepine play a role in the mechanism of the stabilizer process by acting as UV absorber. The UV light absorption by these additives containing 1,3,4-thiadiazole dissipates the UV energy to harmless heat energy (SchemeIII). The ring of 1,3,4-oxadiazole in this compound plays a role in the mechanism of the stabilizer process by acting as 


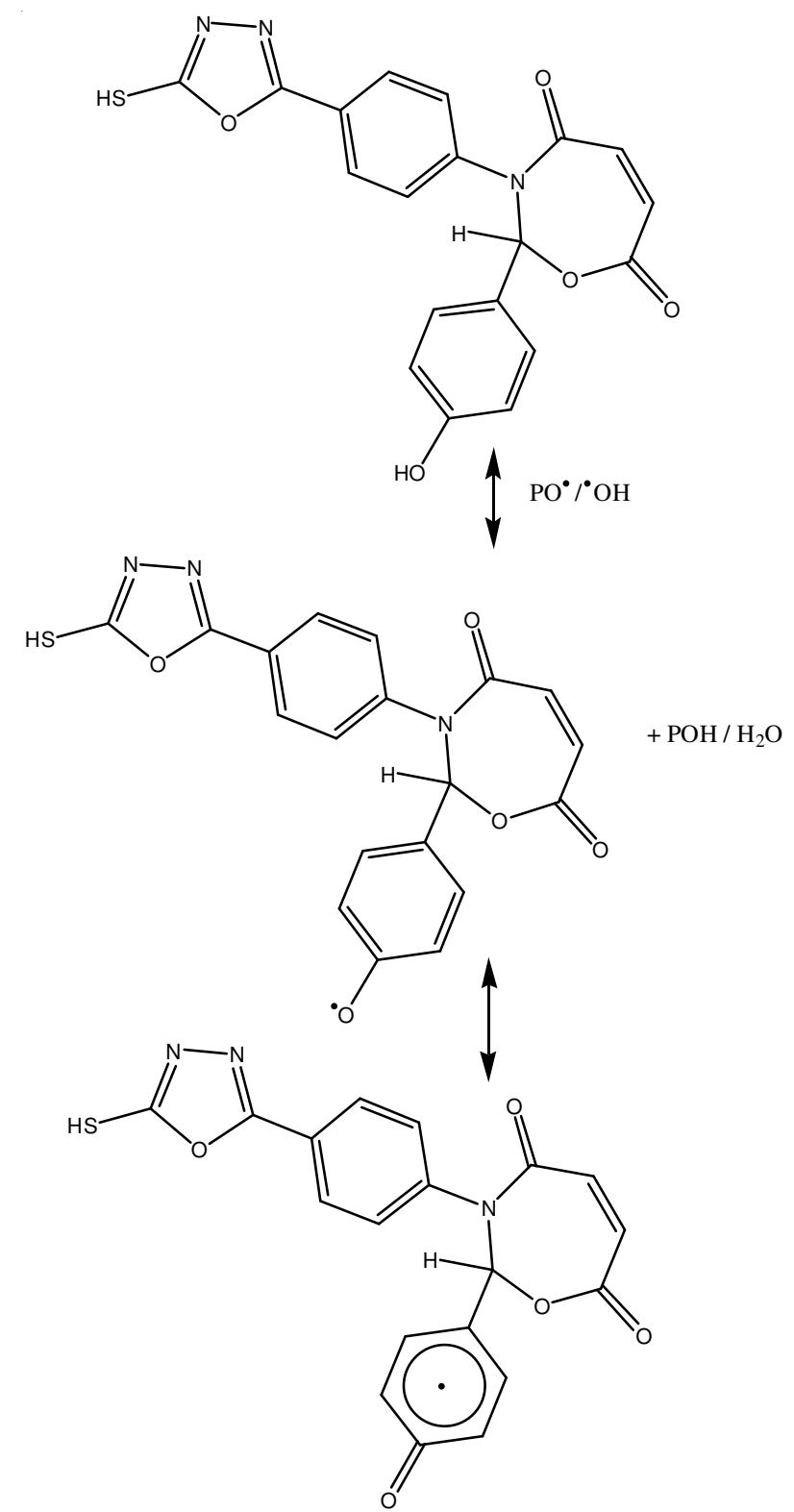

Scheme-II: Suggested mechanism of photostabilization of PVC by compound $\mathbf{1}$ as radical scavenger

UV absorber. The UV light absorption by these additives containing 1,3,4- oxadiazole dissipates the UV energy to harmless heat energy (Scheme-IV), which support these compounds as photostabilizer.

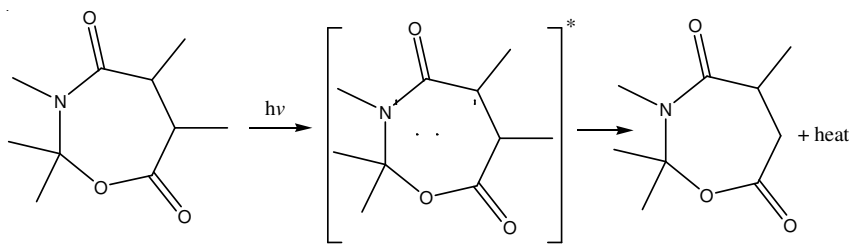

Scheme-III: Suggested mechanism of photostabilization of 1,3-oxazepine ring as UV absorber

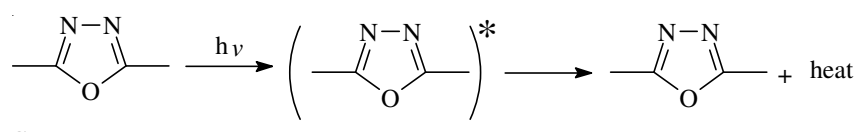

Scheme-IV: Suggested mechanism of photostabilization of 1,3,4oxadiazole ring as UV absorber

\section{Conclusion}

In present work, the photostabilization of PVC films using 1,3-oxazepine compounds were studied. These additives behave successfully as photostabilizer for PVC films. The additives take the following order in photostabilization activity according to their decrease in hydroxyl index for PVC films.

$$
[\text { I }]>[\text { III }]>[\text { III }]>[\text { IV }]
$$

These additives stabilize the PVC films through UV absorption or screening, peroxide decomposer and radical scavenger mechanisms. The compound $\mathbf{1}$ was found to be the more efficient in photostabilization process according to the photostability and mechanisms mentioned above. These mechanisms support the idea of using 1,3-oxazepine compounds as commercial stabilizer for PVC.

\section{ACKNOWLEDGEMENTS}

The authors are grateful to Universiti Kebangsaan Malaysia for funding (Codes AP-2011-17, DPP-2013-054 and UKMMI-OUP-2011).

\section{REFERENCES}

1. A. Khalafi-Nezhad and A. Hashemi, Iran. J. Chem. Chem. Eng., 20, 9 (2001).

2. A. Corradi, C. Leonelli, A. Rizzuti, R. Rosa, P. Veronesi, R. Grandi, S. Baldassari and C. Villa, Molecules, 12, 1482 (2007).

3. K. Bougrin, A. Loupy and M. Soufiaoui, J. Photochem. Photobiol. C, 6, 139 (2005).

4. P.V. Frank, K.S. Grish and B. Kalluraya, J. Chem. Sci., 119, 41 (2007).

5. A. Loupy, G. Bram and J. Sansoulet, New J. Chem. Lett., 386, 7029 (1992).

6. A.L. Andrady, S.H. Hamid, X. Hu and A. Torikai, J. Photochem. Photobiol. B, 46, 96 (1988).

7. A.L. Andrady and N.D. Searle, J. Appl. Polym. Sci., 37, 2789 (1989).

8. N. Grassie and G. Scott, Polymer Degradation and Stabilization, Cambridge University Press, London (1985).

9. D.J. Harper, J.F. McKellar and P.H. Turner, J. Appl. Polym. Sci., 18, 2805 (1974).

10. E.J. Fadel, M.Sc. Thesis, Tikrit University, Tikrit, Iraq (2010).

11. A.M. Daher and H. Al-Jibory, Ph.D. Thesis, Tikrit University, Tikrit, Iraq (2010).

12. J. Rapek and B. Randy, Photodegradation, Photo-Oxidation and Photostabilization of Polymers (1975).

13. J. Mark, Physical Properties of Polymers Handbook, Springer, New York.

14. F. Mori, M. Koyama and Y. Oki, Angew. Makromol. Chem., 64, 89 (2007).

15. N. Nakajima, M.R. Sadeghi and T. Kyu, J. Appl. Polym. Sci., 41, 889 (1990).

16. A.V. Shyichuk and J.R. White, J. Appl. Polym. Sci., 77, 3015 (2000).

17. F. Gugumus, Mechnism of Polymer Degradation and Stabilization, Elsevier, Amsterdam (1990).

18. J. Salimon, N. Salih, E. Yousif, A. Hameed and H. Ibraheem, Aust. J. Basic Appl. Sci., 4, 2016 (2010).

19. R. Rasheed, H. Mansoor, E. Yousif, A. Hameed, Y. Farina and A. Graisa, Eur. J. Sci. Res., 30, 464 (2009). 